\title{
A Critical Review on Lightweight Design of Battery Pack Enclosure for Electric Vehicles
}

\author{
Ashvin Dhoke $^{1^{*}, \text { Amol Dalavi }^{1}}$ \\ ${ }^{1}$ Department of Mechanical Engineering, Symbiosis Institute of Technology, Symbiosis International (Deemed) \\ University, Gram Lavale, Mulshi, Pune 412115, India \\ *Email: Ashvin.Dhoke.PhD2020@sitpune.edu.in
}

\begin{abstract}
An electric vehicle battery pack which is a gathering of battery modules which subsequently comprised of the battery cell is a primary source of control transmission for an Electric Vehicle (EV). The inappropriate design of the battery enclosure will cause many genuine issues, such as cracking, causing noise, or battery harm. At the same time, the weight of the battery enclosure is huge; in order to get better the driving range of the electric vehicle and diminish the influence of the battery on the vehicle dynamic performance and acceleration performance, it is essential to carry out the lightweight design of the battery enclosure. This paper reviews the multi-material battery enclosure design optimization, the multi- technologies, and a proficient Battery Management System (BMS) for compact battery pack design used to lightweight battery pack enclosure design; the multi-objective optimization approach for distinctive parameters of battery pack enclosure design optimization by diverse manufacturing techniques.
\end{abstract}

\section{Keywords}

Electric vehicle; Battery pack enclosure; Light weight; Multi-objective optimization

\section{Introduction}

Electric vehicles (EVs) offer propulsion using the energy stored in batteries on-board and they are implicit in being highly competent in converting stored electrical energy into mechanical energy compare to that of conventional internal combustion engine vehicles (ICEVs). Based on the source of the energy, EVs are one of the solutions to be an emission-free propulsion system. Accordingly, the growth of EVs has to deal with the difficulty of the heavily weighed battery packs and the security concerns of the battery. A promising approach is the incorporated lightweight structure of future battery packs in order to get the protection requirements as well as generate a satisfactory driving range [1]. The battery pack enclosure secures and underpins the power battery; it plays a key part in guaranteeing the security of EVs. The inappropriate design of the battery enclosure will cause in many genuine issues, such as cracking, causing noise, or battery damage. At the same time, the weight of the battery enclosure is huge; in order to get better the driving range of the electric vehicle and diminish the influence of the battery on the vehicle dynamic performance and acceleration performance, it is essential to carry out the lightweight design of the battery enclosure [2].
EV security is a genuine concern that is subordinate to the battery pack. Battery pack safety depends on its mechanical characteristics, such as its potential to resist deformation and vibrational frequencies. In case it cannot fit the realistic requirements, the battery might breakdown and explodes. Hence, researching the shape transformations and mechanical behavior of enclosures is vital for the security of the vehicle too, the vehicle with less weight is favored because it spares space for other components and indeed increases the space for battery packs so as to reinforce the cruising capacity of EVs. To illuminate the previously mentioned issues, studies were carried out on the state of charge checking of batteries, development of electrode materials, thermal runaway and overheating, and hybrid energy storage system [3].

An effective design of battery pack and its components by integration of most favourable scenario for materials, state of health (SOH), configurations (assembly), thermal (air and liquid cooling), and battery pack enclosure mechanical security, and recycling. Figure 1 shows a schematic of an advanced battery pack design technique. In the production stage of batteries, different electrode materials require to be considered to achieve higher capacity. In the battery gathering stage, it is essential to consider the difference in capacity caused by battery performance irregularity. Within the battery operation stage, it is 
essential to consider the $\mathrm{SOH}$ of the battery, anticipate thermal runaway, and guarantee the mechanical strength of the battery pack casing. In the battery recycling stage, it is vital to consider more sophisticated battery recycling methods to diminish environmental pollution and lessen recycling costs [4].

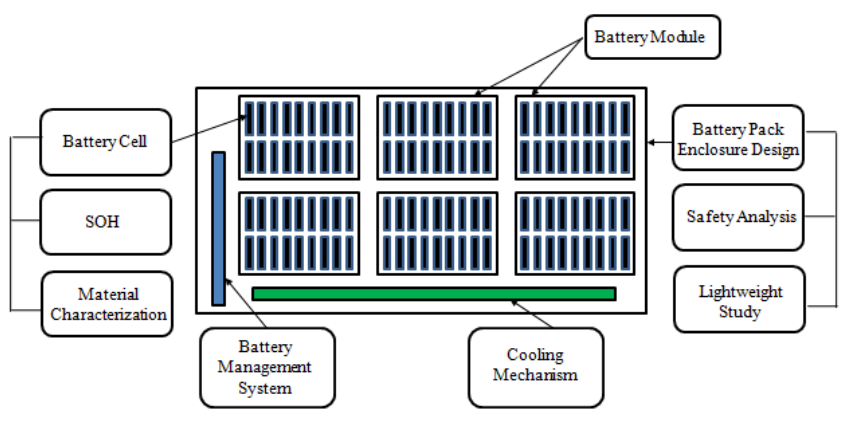

Figure 1 Schematic diagram of an advanced battery pack design [4]

The main objective of this literature review is to find out answers to following questions,

1. What are the current trends of battery pack enclosure design?

2. What are the different materials and manufacturing processes used for battery pack enclosure design?

3. What are the different loading scenarios and conditions considered for battery pack enclosure design?

4. What are different optimization algorithms and techniques used for structural design and process optimization?

5. What are the different parameter performance effects due to battery pack design at vehicle level?

6. Which are the future directions for the development of the lightweight design of battery pack enclosure based on the current research gap?

This paper presents an outline of literature found on battery pack enclosure design, the development trends at present, the multi-material battery enclosure design optimization using new materials like high strength steel, carbon fiber composite, plastic, and aluminum alloy to achieve a lightweight design of the battery enclosure; the multi-objective optimization techniques used to lightweight battery pack enclosure design by minimized mass, maximized natural frequency, minimized deformation and minimized stresses in enclosure structure under vibration, shock loading, impact loading (crash loading scenario); the multiobjective optimization technique for distinctive parameters of battery pack enclosure design by diverse manufacturing technologies for low cost and high strength; an efficient Battery Management System
(BMS) for a compact battery pack for high cooling performance.

\section{$2 \quad$ Literature Review}

The security issue of the EV industry is the foremost basic challenge to attain large-scale industrialization. Lithium-ion batteries are right now the foremost broadly utilized power battery in the EV industry. Be that as it may, lithium-ion battery packs are inclined to security issues due to mechanical vibration transmission, external load shock, and thermal runaway. The excellent mechanical properties of the battery pack provide a more prominent degree of security and enhance the safety of EVs. The battery pack enclosure, as a vital boundary to maintaining the structural reliability of the battery pack, has gotten more consideration from EV producers [5] and lots of studies have done on efficient and lightweight design of battery pack enclosure by researcher worldwide.

\subsection{Battery Pack Enclosure with Different Material and Manufacturing Aspect}

Li et al. displayed the standard power battery box of aluminium alloy material for electric bus is consider to ponder mechanical characteristics like deformation and frequency by the finite element method, analytical results gives the information for the optimization of the consequent standardized battery box [6]. Delogu et al. considered lightweight arrangements based on composites and hybrid materials whose high mass lessening potential is anticipated to be especially productive within the EV components like chassis and body parts [7]. Muttana et al. displayed imaginative concept like utilize of body panel material as Graphene for energy storage, Graphene could be material of a single layer of carbon atoms, has more strength than diamond, is lightweight and is adaptable. Graphene has the potential to invigorate more maintainable transport with light and ultra-efficient batteries and could be utilized in ultra-capacitors, solar cells, and as lightweight materials for vehicle body applications [8]. Jung et al. displayed the direct-drive powertrain and in-wheel engines of EV have lower fuel utilization for a given estimate of the battery, compared to a more customary drivetrain, since of decreased vehicle weight and lower misfortunes within the drivetrain [9]. Mayyas et al. illustrated an arrangement of a lightweight design by means of magnesium body-inwhite (BIW) in expansion to pure electric drivetrain would grant the most elevated carbon dioxide emissions than that of lightweight options like aluminum BIW and electrified powertrain alternatives [10]. Zhao et al. used the ABAQUS Simulation tool to conduct strength analysis and optimization using battery box structure material as composite and 
Aluminum alloy. Optimization results show that the composite material box structure will reduce the weight by $42 \%$ compared to that of aluminum alloy [11]. Sahraei et al. demonstrated that a really great relationship was gotten between LS-DYNA numerical results and actual test data for thin pouch battery enclosure for the through-thickness compression, punch indentation, and restricted compression loading. Design changes in pouch battery enclosure like structural reinforcement, altered the deformation and failure mode of the system [12]. Chen et al. presented the multi-material battery enclosure optimization by means of materials like carbon-fiber-reinforced plastic (CFRP) and aluminum alloy. The optimized design depicts the mass of the new design of the battery pack enclosure is reduced by $48.86 \%$ with enhancement in vibration performance [2].

Zwicker et al. draw an overview of diverse joining advances in the field of battery manufacturing and challenges happened whereas joining for the battery pack, ultrasonic welding is reasonable especially for joining pocket cells, wire holding is reasonable for huge modules containing small cylindrical cells, but not for connecting prismatic or pouch cells. Laser welding is additionally pertinent for cylindrical cells but maybe less pertinent when joining huge cells with expensive geometrical interconnectors [13]. Berjoza et al. illustrated a technique for deciding the range and dynamic parameters of electric vehicles depending on changes within the fundamental weight of the vehicles [14]. Hofer et al. displayed an expository arrangement to discover the ideal sum or costing of lightweighting in a battery electric vehicle (BEV) [15].

Arora et al. presented a study on the concept of the mechanical design of a battery pack for E-bus. The study depicts how mechanical design elements influencing the security and reliability of EV battery packaging. Additionally, how factors like mechanical vibration, impact energy, and temperature variation interact with the battery pack through an interface. This interaction would be restricted for secure and reliable operation of the battery pack by limiting cell movement. Furthermore, this study reveals the significance of adopting modularity in battery pack design and the significance of packaging space in EV [16].

Arora presented a robust design methodology for enhancing the reliability of modular EV battery packs. Battery polarization models (Newman, Tiedemann and Gu model, also known as the NTG model) is used in this study. A test considers carried out assessing the impact of nominal capacity on heat generation to create input data for the model development process. A new computational model is planned based on artificial neural networks (ANNs) for the evaluation of heat generation rates of $\mathrm{Li}$-ion battery cells of diverse nominal capacities. The results depict thermal management system design and battery packaging design has the foremost impact on the modularity of battery packs; battery pack modularity such as battery cell movement, thermal runaway spread, thermal barriers, lateral and vertical reinforcements to battery packs to avoid harm due to mechanical vibration and fitting of the battery pack on chassis from crash and safety aspect. ANN architecture can forecast heat generation for pouch cells with good accuracy for discharge rates. Better thermal performance can be obtained by means of battery cell orientation and thermoelectric coolers [17].

\subsection{Battery Pack Study with Different Optimization Algorithms}

Pal et al. used a multi-objective genetic algorithm (MOGA) to optimize the design of a battery pack enclosure with cold sprayed material properties. The objectives of optimization were minimizing deformation, maximization of frequency to avoid resonance conditions, and minimization of battery pack enclosure mass. The optimization results for cold sprayed aluminum material were compared with the results obtained using bulk aluminum [5]. Wang et al. used Pareto solutions for multi-objective topology optimization to optimize the design of the traction battery enclosure. An optimization result depicts a mass of battery enclosure for the new structure decreased by $9.42 \%$ to that of the original structure [18]. Lin et al. presented efficient and expound surrogate-based optimization technique for an aircooling battery pack. A multi-objective optimization problem is actualized utilizing the metamodel technique and at the same time, the multi-objective particle-swarm-optimization (MOPSO) algorithm is minimized the total mass and maximized the basic frequency. The optimal schemes consequent based on optimization is demonstrated their improved structure performance for the new design than that of the baseline design [19]. Shahin et al. presented a methodology where ANSYS is used for the battery pack enclosure design for specific electric vehicle study and MATLAB is utilized for the implementation of genetic programming (GP) for conditioning the design parameters. Optimizations ponder carried out for models for the objective of minimization of mass, maximization of natural frequency and minimization of deformation using genetic programming [20]. Cui et al. presented a methodology where multi-gene genetic programming is utilized to evaluate the data at the cell level and prepare a model for lithium-ion battery capacity. Optimization ponder carried out on battery 
pack enclosure design considering non-dominated sorting genetic algorithm (NSGA-II).The results depict the enhanced performance of NSGA-II when combined with other artificial intelligence algorithms like ANN. The battery pack enclosure optimizes design shows enhanced performance as the maximum deformation diminished by $22.22 \%$ and mass of optimized enclosure is diminished by $11.61 \%$ [21].

Shui et al. proposed a design optimization methodology where ANSYS tool utilized for Strength and Modal Analysis for deformation and natural frequency results to optimize battery pack enclosure design. The combination of four methods (i.e., central composite design (CCD) and response surface methodology (RSM), CCD and artificial neural network (ANN), Latin hypercube sampling (LHS) and RSM, LHS and ANN is utilized to developed mass minimizations for battery pack enclosure. The best combination of methodology (CCD and ANN) is utilized for the formulation of the mechanical design model. The models based on CCD and ANN for the maximum deformation, minimum natural frequency, and mass are further optimized by utilizing a nondominated sorted genetic algorithm (NSGA II). The battery pack enclosure optimize design depicts a reduced value of maximum deformation by $2.22 \%$, the improved value of minimum natural frequency by $3.18 \%$ and diminish in mass by $11.61 \%$ from its standard design [22].

Ruhatiya et al. presented the different predictive modeling strategies like linear regression, regression with AdaBoost, decision tree regression and multilayer perceptron (MLP) are used to forecast the deformation, natural frequency and mass of battery pack enclosure. The decision tree regression model was chosen for deformation, MLP with tanh function for frequency and MLP with ReLU function for mass by performing the comparative examination of these methods. Chosen models were optimized using a nondominated sorting genetic algorithm (NSGA II). An optimization result depicts the design of the battery pack enclosure with the maximum deformation $(0.0019 \mathrm{~m})$, mass $(12.41 \mathrm{~kg})$ and minimum natural frequency $(91.60 \mathrm{~Hz})[3]$.

Li et al. presented an optimization approach for effective design of battery pack and its components by integration of most favourable scenario for materials, state of health (SOH), configurations (assembly), thermal (air and liquid cooling) and battery pack enclosure mechanical security and recycling. The optimization results depict accuracy of $\mathrm{SOH}$ forecast based on stress-based GP achieved more than $90 \%$ for the air-cooled system, the maximum temperature difference of the eight battery cells was decreased by $51.9 \%$ and for the liquid-cooled system, the pressure drop was reduced by $44.53 \%$. Battery pack enclosure mechanical characteristic, the maximum deformation was diminished by $22.22 \%$, the minimum natural frequency was enhanced by $3.18 \%$ and the weight was decreased by $11.61 \%$ [4].

Pan et al. used LS-DYNA for crush and crash simulations for battery pack enclosure design with material of steel and carbon-fiber-reinforced plastic. An Optimization is done to get optimize the design of the battery pack enclosure for crush loading. The result implies both the materials and thickness of the components influence the crush and crash behaviour. The weight of the battery pack enclosure was decreased by $6.6 \%$ and the crashworthiness performance improved [23]. Uerlich et al. used LSDYNA for simulation and investigation of the crushing characteristics of the battery pack for distinctive geometries subjected to static and dynamic loads. An investigation had done with the deformation mechanism of three distinctive geometric batteries packs in a side pole impact loading scenario. The results depict hexagonal pack geometry is showed superior performance for the space occupancy rate; it can contain more cells than that of the rectangular module. Hexagonal pack geometry increases its energy absorption characteristics in all working cases. Hexagonal has a more value of specific energy absorption (SEA) than that of other geometries like the rectangular and trapezoidal pack [1].

Li et al. presented a methodology that consist of four areas; ANSYS used for the design of air-cooling battery, CFD codes, design of experiments (DoE) and surrogate models for evaluation and selection. The optimum scheme for air cooling battery module is selected through multi-objective optimization. The optimized air-cooling battery module reveals drastically lower temperature rises for each cell than the initial scheme. This study implies a practical idea to design a battery thermal management system with improved cooling effect and less occupancy of space and industrial EVs can incorporate this optimized model where the battery pack consists of a high number of cells [24].

Svens presented the test equipment developed for battery cell testing for conventional vehicles. Test equipment used to evaluate real-time performance of cell level battery testing on-board conventional heavyduty vehicles with a low cost and relatively faster than in-field testing. The test results reveal that the hybrid strategy can deliver comparatively high cycled energy per driving distance even for intercity traffic driving 
while the state of charge (SOC) window is shifted towards the lower limit. A flexible battery packaging material regarding resistance to water intrusion on commercial lithium-ion battery cells and shows potential results. No elevated water intrusion level was found even after vibration and temperature cycling of the battery cells [25].

Grunditz demonstrated a mathematical model of Vehicle Dynamics to study acceleration performance. Finite Element Analysis (FEA) and Computational Fluid Dynamics (CFD) methods were utilized for heat transfer analysis in electrical machines. The acceleration performance, energy consumption, and efficiency of the powertrain, comprising a traction motor, a power electronic module and a battery were evaluated for the different drive cycles. The results imply down scaling of the electric power train caused a decrease in energy consumption to $94 \%$ to that of the original powertrain size and the small slot geometry had more peak losses during the drive cycles despite this a cycle average case had the lowest losses for many cycles [26].

Arora et al. presented robust design methodology a value-based conceptual analysis approach was utilized to analyze design aspects connected to battery cell type and size, packaging architecture, thermal management solution of the modular EV battery pack. The result implies that the battery thermal management system and packaging architecture are the two most significant parameters having the biggest effect on the reliability of EV battery packs. Great emphasis was given on mechanical modularity via thermal modularity of EV battery packs for the successful accomplishment of modular architecture [27].

Omariba et al. used cell balancing algorithms, the algorithms abdicate into active or passive cell balancing methods appropriate to balancing batteries. The battery balancing performance throughout longterm was analyzed for various temperature and vibration frequencies [28].

\subsection{Battery Pack Performance Study at Vehicle Level}

Becker et al. presented single pack and hybrid battery systems battery dimensioning and optimization techniques. An evolutionary optimization algorithm and a detailed modular Matlab-Simulink vehicle model were used for optimization. The best single pack approach works as a reference as well as the best hybrid battery approach was evaluated for each vehicle. The results imply that the weight advantage for hybrid battery system was up to $11 \%$ for the smaller cars, but up to $20 \%$ for SUV and the volume reduction achieved up to $5 \%$ for the compact car with $300 \mathrm{~km}$ range and up to $31 \%$ for the medium sports vehicle. The cost-saving achieved using hybrid battery systems up to $5 \%$ for the compact vehicle and up to $24 \%$ for the SUV [29].

Larrodé et al. used Multi-body Dynamic (MBD) software tool Adams Car to build electric vehicle model called Gorila. MBD model was analyzed and studied the design requirement for electric vehicles to optimize engine power, weight, battery, and vehicle performance according to the typical urban routes characteristics [30]. Xin et al. presented optimal design using minimum curb mass as the integrated design principle. An optimization simulation tool, CRUISE, was utilized to analyze the sensitivity of electric vehicle mass to power consumption. The result implies the decrease of curb mass can efficiently decrease energy consumption. The result conveys that with the guarantee of dynamic performance, the power consumption can diminish by $7.21 \%$ [31]. Mareev et al. used Matlab/Simulink software tool to create a simulation model of a battery-electric truck. The simulation model had a route model, driver model, driving resistances model, drivetrain model and battery model. Additionally, a graphical user interface was developed to parameterize the model and to evaluate the simulation results. This model was utilized to predict energy consumption and to dimension the battery capacity. The investigation results imply the required battery capacity of battery-electric trucks was limited payload to only $80 \%$ of conventional diesel trucks considering the necessities of long-haul transportation; same life cycle costs for battery-electric trucks and conventional diesel trucks in distinctive transportation scenarios [32]. Lorf used MATLAB and MATLAB Simulink for modeling and simulation of electric vehicle and battery models. Experimental methods were used in this study, one for Racing Green Endurance (RGE) Project and the other for battery testing. The result implies average driving force $F_{d}$, range $\mathrm{d}$, and battery degradation are factors affecting to optimum nominal battery capacity. The product of the average driving force and range was equated to the optimum nominal battery capacity, which was constant. In comparison, battery degradation was affected the optimum battery capacity linearly with time. The expected life of the battery Pack was estimated based on EV annual mileage of 15,000$25,000 \mathrm{~km}$ and a lifespan of EV is around 7-10 years, the total vehicle mileage is between 105,000-250,000 $\mathrm{km}$. For all-electric ranges of $150-700 \mathrm{~km}$, this translates into 150-1,700 full battery cycles. Empirical evidences have revealed that capacity weakens mostly linear and ranges between $0.05-0.3$ per cycle for lowcapacity cells discharged at $20 \%$ depth of discharge 
(DOD) up to $0.03-0.05 \%$ per cycle for high-capacity cells discharged at full capacity [33].

Holjevac et al. used the Archive-based Micro Genetic Algorithm (AMGA) to carry out the optimization. The multi-objective optimization with parameters like vehicle's consumption, emission, range, longitudinal and lateral dynamics, costs and performances to widely assess the vehicle. An optimization result implies hybrid electric vehicle HEV represents a compromise solution between BEV and ICEV. However the ICEV still represents the most efficient solution for low-cost vehicles [34].

Feng et al. presented Proton Exchange Membrane Fuel Cell (PEMFC) battery hybrid electric vehicle is considered for optimal design and control development. The tri-level optimization problem was defined for identifying the optimal powertrain component sizes and energy management parameters, and an advanced surrogate-based global optimization method was utilized to simulate the complex optimization problem. The optimization results convey a balanced solution with reduced hydrogen fuel consumption and with extended PEMFC; battery life increased by $8.7 \%$ of the mining tonnage specific cost from $\$ 0.41 / t$ to $\$ 0.37 / t$. The PEMFC degradation cost decreased from $\$ 2.41$ to $\$ 1.00$ per operation cycle and the battery degradation cost was decreased from $\$ 8.09 \mathrm{e}-5$ to $\$ 4.19 \mathrm{e}-5$ per operation cycle [35].

Hou et al. presented the total cost of ownership TCO model is also known as the cash flow model. This model consists of battery, fuel, electricity, and salvage costs. A battery degradation-based salvage model is presented and a distinctive investigation is worked out. Fuel price and battery price are the two most important economic parameters in the TCO curve. A $10 \%$ rise in fuel price will contribute an additional $7.5 \%$ and $0.2 \%$ to the TCO of plug-in hybrid electric vehicles (PHEVs) with batteries of $2 \mathrm{kWh}$ and $24 \mathrm{kWh}$, respectively; a $10 \%$ rise in battery price will enhance the TCO of PHEVs with batteries of $2 \mathrm{kWh}$ and 24 kWh by $2 \%$ and $8 \%$, respectively [36].

Xue presented a design of the PHEV battery pack that is used for three different optimization problems 1) battery mass minimization, 2) battery volume minimization, and 3) battery material cost minimization. Augmented lagrangian particle swarm optimization (ALPSO) is a population-based optimization method is utilized for optimization. The result implies the single cell design optimization was competent to quantify the variations of morphological parameters as a constant active mass ratio; the plug-in hybrid vehicle battery design presents an automated design process that considers realistic performance constraints. The multi-cell design approach minimizes the battery pack mass by utilizing separate cell designs to satisfy different constraints [37].

Erb presented a fluid dynamics solver COMSOL is used for simulation for model based on Tube Bank Theory. Additionally, ADVISOR Advanced Vehicle Simulator developed by the National Renewable Energy Laboratory (NREL) is used for simulation of energy storage power versus time. Deterministic dynamic programming (DDP) is used to optimize power split between two sources, such as an engine and a motor in a hybrid vehicle. In this study, distinctive classification methods are used like the Naive Bayes Classifier as a baseline and $k N N$ for enhanced performance for collaborative learning. The study gave an insight of how cell-level properties affect the overall costs of air-cooling in battery packs and how to minimize those costs through both simulation and analytical studies; how much improvement is possible for different hybrid applications using current energy storage technology; how collaborative learning can add advantage to energy management for hybrid vehicles. Identification of parameters those are most useful in predicting an idle time of vehicles in traffic by defining a traffic model and comparing that to real-world datasets [38].

Solomon et al. draw a review on the methods for improving the efficiency of Electric Motor by using lightweight materials, novel manufacturing processes, different magnetic materials and different cooling methods [39]. Tuncay et al. used the Matlab SIMULINK model of an in-wheel motor-driven hybrid electric vehicle to evaluate the performance values. The mechanical differential is supplanted by an electronic control technique. The preliminary laboratory and on-road experimental studies are carried out on Fiat Linea vehicles. The design optimizations had done for ICE, Electric Drive and Battery Power for different drive cycles [40].

\section{$2.4 \quad$ Research Gaps}

Based on above literature study, there are research gaps found as follows,

1. Generic gravity loading, weight, and vibrational loading were considered for battery pack enclosure design. There was hardly any evidence found on actual test load cases and impact loads for design optimization [22].

2. Battery pack enclosure design optimization study done by considering material like steel, high strength steel, aluminum, magnesium, plastic as 
well as composite but no study was observed on a lightweight structure like honeycomb which is used in aircraft design [2].

3. There were research papers on optimization algorithm model of ML and AI like artificial neural network (ANN) used for the study of the mechanical features and parameters (reduction of deformation and weight) of battery pack enclosure design but without consideration of efficient cooling system, placement of battery pack enclosure, the mechatronic mechanism to allow the main circuit of an electric vehicle to get disengaged in the case of fire in the battery modules and sensors integration of battery pack system for estimating the temperature distribution, charging state and health state of modules in realtime. If studies have been made with all factors considered for optimization for battery pack design, that would be real-time scenario [22].

4. Most of EV's battery thermal management study had done with a natural cooling mechanism which was less effective for temperature distribution which causes failure of battery performance, so needs to study more effective ways of the cooling mechanism of battery to improve life [38].

5. The life cycle costs of battery-electric trucks and conventional diesel trucks were compared based on parameters like route model, driver model, driving resistances model, drivetrain model and battery model. This study would be more effective if it's done with charging infrastructure parameter [32].

6. Different battery cell balancing method optimization techniques were studied for various temperature and vibration frequencies but there were no experimental validation done for results verification [28].

7. Various joining process were studied for battery pack manufacturing and identified which one suitable for respective battery cell. In this study, there were no considerations of different material used for joining techniques for battery pack enclosure manufacturing [13].

8. There were studies on battery dimensioning and optimization approach for single pack and hybrid battery systems for different vehicle segment. Study showed advantage of hybrid battery pack for weight, range and cost saving over single pack. This hybrid pack advantages could be further evaluated by considering modular battery pack which can be used range of vehicle from electric car to heavy duty truck application [29].

9. Studies had done on battery pack energy storage power versus time using the ADVISOR Advanced Vehicle Simulator for lithium-ion battery chemistry. This study could be more effective if the computational model would have become more robust if other chemistries like lithium cobalt oxide and lithium nickel-manganese oxide were considered [17].

10. Vehicle level simulation was done in MATLAB Simulink for factors affecting optimum nominal battery capacity. It was found that battery degradation was affected the optimum battery capacity linearly with time for a certain level of depth of discharge. This study could be further extended with long-term dynamic cycling using similar Li-ion cells and applying different levels of depth of discharge [33].

11. Most of battery packs enclosure design optimization study done with Finite element (FE) model in simulation tool by considering random vibration, mechanical shock and crash loading. Further study needs to carry out for FE model validation with actual test results. This validation would improve the confidence level on the accuracy of results [23].

12. There were multiple studies found on electric passenger car battery pack enclosure design optimization and lightweighting, but very limited research were found on heavy-duty electric truck battery pack enclosure design optimization [32].

\section{Future Research Directions on Battery Pack Design}

The following are future research directions for an EV battery pack,

\section{Battery Pack Design for Test Condition}

Most battery packs enclosure designs considered mechanical tests like deformation and vibration loading. However, battery needs to perform in real scenario loading so more detailed study needs to carry out for tests condition for elevation and external forces like compressive, tensile and torsion due to crash as design optimization parameters.

\section{Battery Pack Enclosure Lightweight Design}

Lightweight battery pack design is need of time to improve the range of the electric vehicle. Different Materials like composite and Honeycomb can be considered for battery pack enclosure lightweight design. There is high potential to save weight of the structure by Honeycomb as it is light in weight and it has shock-absorbing capacity to avoid failure from shock loading. Topology optimization techniques can also be applied for further weight reduction from the structure. 
3. Battery Pack Enclosure Placement in Vehicle

Location for battery pack enclosure in Electric Vehicle can be optimized based on safety requirement of the vehicle. The location should be decided based on crash consideration where it will get minimum damage during the accident and its working should not hamper. This is also a potential area for research in battery pack enclosure design optimization.

4. Battery Pack Enclosure Manufacturing Feasibility and Layout Space

Manufacturing feasibility/process and layout space as design parameters to be considered for design optimization. Different material selections are there for design optimization, but specific manufacturing process factors which affect overall design and battery pack enclosure layout space like how module and other systems (BMS and cooling mechanism) place inside enclosure are very important of design optimization.

5. Battery Pack Enclosure with Efficient Cooling Mechanism

An optimization with temperature as a design parameter can be considered because irregular temperature distribution in the module may cause fire and lessen the life of battery. The effective cooling system like air and water cooling is required to be optimized other than the mechanical characteristics. Efficient cooling mechanism also improves the battery life.

\section{Smart Battery Pack Design}

Battery pack enclosure with embedded a mechatronic mechanism can be designed to permit the electric vehicle main circuit to cut-off in the case of fire. Intelligent product development with the installation of sensors and integration of battery pack system with models for predicting the temperature distribution, charging state and state of health for modules in real time scenario. This is another potential research area for development of smart battery pack for future requirement.

\section{Battery Pack Design for Recycling}

Developments of Battery pack disassembly process and battery material recycling process. The battery pack design should be such that it should easily disassembly without any damage to the battery pack so that it efficiently recycles for further usage. Recycling is a major business for the second usage of the battery.

8. Battery Ageing Mechanism

The battery aging mechanism is still a new area to work it involves multidisciplinary investigation like chemical, electrical and mechanical aspects to develop an analytical model for further study.

9. Battery Pack Design with Advanced Optimization Algorithms

Advanced Machine learning and Artificial Intelligence algorithms can be utilized to improve the efficiency and productivity of optimization methods. Advanced optimization algorithms predicting results with high accuracy and can handle huge amount of data of different parameters needs to be consider for multidisciplinary optimization. This has a high potential area for recent research.

\section{New Battery Technology}

There is lots of development needed in lithium-ion battery technology to meet the range target for electric vehicles. The development of battery technology will increase capacity, range and reduce the cost of the battery for a heavy-duty electric truck. Cost-effective batteries will improve EV business around the world Battery technology is one of the most potential area of research now.

\section{Battery Pack Design Modularization}

The development of battery pack modularization is a very important aspect as it can be used for wide range voltage requirements and can be used in high voltage battery-electric trucks. Battery pack modularization is one of the most potential research areas as it will save cost and design time in overall development for a wide range of electric vehicles.

\section{Battery Pack Design Test Setup}

Validating results of finite element (FE) model for battery pack enclosure with experimental tests with distinctive loading cases like random vibration, mechanical shock, and crashworthiness. Simulation methodology can be developed based on the correlation of FE simulation and test results. Battery balancing performance can also be 
validated through experimental test results for efficient design optimization.

\section{Conclusion}

This paper presents a critical review on the design of battery pack enclosure using lightweight material or multi-materials optimization, multi-objective optimization techniques, novel manufacturing processes, cooling methods for efficient Battery Management System (BMS). Light weighting of battery pack enclosure for EV is important to enhance the range of EV and the life cycle of a battery pack. Battery Pack is the primary source of power transmission for Electric Vehicle (EV) and it speaks to increase innovation in the long run. In this manner, indeed, in the event that there is still a long way to go, the hope of the authors is that this becomes a progressively more consolidated technology and that improved the range of EV and the life cycle of a battery pack. An efficient battery pack design can constitute a reply to the issues associated to it.

\section{References}

[1] R. Uerlich, K. Ambikakumari Sanalkumar, T. Bokelmann, and T. Vietor, "Finite element analysis considering packaging efficiency of innovative battery pack designs," Int. J. Crashworthiness, vol. 25, no. 6, pp. 664-679, 2020.

[2] X. Chen, M. Li, S. Li, J. Jin, and C. Zhang, "Design optimization of multi-material battery enclosure for electric vehicle," Lect. Notes Electr. Eng., vol. 486, pp. 853-864, 2019.

[3] C. Ruhatiya, P. N. Gia Bao, T. L. Quan, Q. T. Tho, and L. Xinyu, "A hybrid multi-output-predictive modelling based NSGA II approach for dimensions design optimization of battery pack module for electric vehicles," Energy Storage, vol. 2, no. 3, pp. 1-12, 2020.

[4] W. Li et al., "Intelligent optimization methodology of battery pack for electric vehicles: A multidisciplinary perspective," Int. J. Energy Res., vol. 44, no. 12, pp. 96869706, 2020.

[5] S. K. Pal, S. Singh, H. Singh, M. L. Le Phung, S. Yooyen, and S. Sleesongsom, "Intelligent design optimization of battery pack enclosure for electric vehicle by considering cold-spraying as an additive manufacturing technology," Energy Storage, vol. 2, no. 3, pp. 1-11, 2020.

[6] J. Li, X. Cao, and L. Guo, "Finite Element Analysis of Power Battery Box Chassis of Electric Bus," J. Phys. Conf. Ser., vol. 1578, no. 1, 2020.

[7] M. Delogu, L. Zanchi, C. A. Dattilo, and M. Pierini, "Innovative composites and hybrid materials for electric vehicles lightweight design in a sustainability perspective," Mater. Today Commun., vol. 13, no. September, pp. 192209, 2017.

[8] S. B. Muttana, R. K. Dey, and A. Sardar, "Trends in Lightweighting of BEVs: A Review of Strategies - Part II," Auto Tech Rev., vol. 3, no. 10, pp. 18-23, 2014.

[9] D. Jung, Q. Ahmed, X. Zhang, and G. Rizzoni, "Missionbased Design Space Exploration for Powertrain Electrification of Series Plugin Hybrid Electric Delivery Truck," SAE Tech. Pap., vol. 2018-April, pp. 1-10, 2018.

[10] A. Mayyas, M. Omar, M. Hayajneh, and A. R. Mayyas, "Vehicle's lightweight design vs. electrification from life cycle assessment perspective," J. Clean. Prod., vol. 167, pp. 687-701, 2017.

[11] X. Zhao, B. Zhang, and S. Zhang, "Lightweight design of battery box for electric vehicle," ICCM Int. Conf. Compos. Mater., vol. 2017-Augus, no. August, pp. 20-25, 2017.

[12] E. Sahraei, R. Hill, and T. Wierzbicki, "Calibration and finite element simulation of pouch lithium-ion batteries for mechanical integrity," J. Power Sources, vol. 201, pp. 307-321, 2012.

[13] M. F. R. Zwicker, M. Moghadam, W. Zhang, and C. V. Nielsen, "Automotive battery pack manufacturing - a review of battery to tab joining," J. Adv. Join. Process., vol. 1, no. March, p. 100017, 2020.

[14] D. Berjoza and I. Jurgena, "Influence of batteries weight on electric automobile performance," Eng. Rural Dev., vol. 16, pp. 1388-1394, 2017.

[15] J. Hofer, E. Wilhelm, and W. Schenler, "Optimal lightweighting in battery electric vehicles," World Electr. Veh. J., vol. 5, no. 3, pp. 751-762, 2012.

[16] S. Arora and A. Kapoor, Mechanical Design and Packaging of Battery Packs for Electric Vehicles, no. 9783319699493. 2018.

[17] S. Arora, "Design of A Modular Battery Pack for Electric Vehicles" Ph.D. dissertation, Centre for Sustainable Infrastructure, Swinburne University of Technology, Hawthorn, Australia, 2017.

[18] L. Wang, X. K. Chen, and Q. H. Zhao, "Muti-objective topology optimization of an electric vehicle's traction battery enclosure," Energy Procedia, vol. 88, pp. 874-880, 2016.

[19] C. Lin, F. Gao, W. Wang, and X. Chen, "Multi-objective optimization design for a battery pack of electric vehicle with surrogate models," J. Vibroengineering, vol. 18, no. 4, pp. 2343-2358, 2016.

[20] M. E. Shahin et al., "An Application of Genetic programming for Lithium-ion Battery Pack Enclosure Design: Modelling of Mass, Minimum Natural Frequency and Maximum Deformation Case," IOP Conf. Ser. Earth Environ. Sci., vol. 268, no. 1, 2019.

[21] X. Cui, B. Panda, C. M. M. Chin, N. Sakundarini, C. Wang, and K. Pareek, "An application of evolutionary computation algorithm in multidisciplinary design optimization of battery packs for electric vehicle," Energy Storage, vol. 2, no. 3, pp. 1-9, 2020.

[22] L. Shui, F. Chen, A. Garg, X. Peng, N. Bao, and J. Zhang, "Design optimization of battery pack enclosure for electric vehicle," Struct. Multidiscip. Optim., vol. 58, no. 1, pp. 331-347, 2018.

[23] Y. Pan, Y. Xiong, W. Dai, K. Diao, L. Wu, and J. Wang, "Crush and crash analysis of an automotive battery-pack enclosure for lightweight design," Int. J. Crashworthiness, 2020.

[24] W. Li, M. Xiao, X. Peng, A. Garg, and L. Gao, "A surrogate thermal modeling and parametric optimization of battery pack with air cooling for EVs," Appl. Therm. Eng., vol. 147, pp. 90-100, 2019.

[25] P. Svens, "Methods for Testing and Analyzing Lithium-Ion Battery Cells intended for Heavy-Duty Hybrid Electric Vehicles,"Ph.D. dissertation, Department of Chemical Engineering and Technology, KTH Royal Institute of Technology Applied Electrochemistry, Stockholm, Sweden, 2014.

[26] E. A. Grunditz,'Design and Assessment of Battery Electric Vehicle Powertrain, with Respect to Performance, Energy Consumption and Electric Motor Thermal Capability," Ph.D. dissertation, Department of Energy and Environment Division of Electric Power Engineering, CHALMERS UNIVERSITY OF TECHNOLOGY, Göteborg, Sweden, 2016. 
[27] S. Arora, A. Kapoor, and W. Shen, "Application of robust design methodology to battery packs for electric vehicles: Identification of critical technical requirements for modular architecture," Batteries, vol. 4, no. 3, 2018.

[28] Z. B. Omariba, L. Zhang, and D. Sun, "Review of Battery Cell Balancing Methodologies for Optimizing Battery Pack Performance in Electric Vehicles," IEEE Access, vol. 7, pp. 129335-129352, 2019.

[29] J. Becker, T. Nemeth, R. Wegmann, and D. U. Sauer, "Dimensioning and optimization of hybrid Li-ion battery systems for EVs," World Electr. Veh. J., vol. 9, no. 2, 2018.

[30] E. Larrodé, A. Torne, and A. Fraile, "Influence of the Design Parameters of Electric Vehicles in the Optimization of Energy Efficiency in Urban Routes," SAE Int. J. Mater. Manuf., vol. 8, no. 2, pp. 398-406, 2015.

[31] X. Xin and Z. Chengning, "Optimal Design of Electric Vehicle Power System with the Principle of Minimum Curb Mass," Energy Procedia, vol. 105, pp. 2629-2634, 2017.

[32] I. Mareev, J. Becker, and D. U. Sauer, "Battery dimensioning and life cycle costs analysis for a heavy-duty truck considering the requirements of long-haul transportation," Energies, vol. 11, no. 1, 2018.

[33] C. F. Lorf, "Optimum Battery Capacity for Electric Vehicles with Particular Focus on Battery Degradation," Ph.D. dissertation, Department of Mechanical Engineering, Imperial College London, 2014.

[34] N. Holjevac, F. Cheli, and M. Gobbi, "Multi-objective vehicle optimization: Comparison of combustion engine, hybrid and electric powertrains," Proc. Inst. Mech. Eng. Part D J. Automob. Eng., vol. 234, no. 2-3, pp. 469-487, 2020.

[35] Y. Feng and Z. Dong, "Integrated design and control optimization of fuel cell hybrid mining truck with minimized lifecycle cost," Appl. Energy, vol. 270, no. March, pp. 115-164, 2020.

[36] C. Hou, H. Wang, and M. Ouyang, "Battery sizing for plugin hybrid electric vehicles in Beijing: A TCO model based analysis," Energies, vol. 7, no. 8, pp. 5374-5399, 2014.

[37] N. Xue, "Design and Optimization of Lithium-Ion Batteries for Electric-Vehicle Applications," Ph.D. dissertation, Aerospace Engineering, University of Michigan, 2014.

[38] D. C. Erb, "Optimizing Hybrid Vehicles: Battery Pack Design , Energy Management , and Collaborative Learning by," Ph.D. dissertation, Department of Mechanical Engineering, MASSACHUSETTS INSTITUTE OF TECHNOLOGY, 2016.

[39] D. G. Solomon, A. Greco, C. Masselli, E. Gundabattini, R. S. Rassiah, and R. Kuppan, "A review on methods to reduce weight and to increase efficiency of electric motors using lightweight materials, novel manufacturing processes, magnetic materials and cooling methods," Ann. Chim. Sci. des Mater., vol. 44, no. 1, pp. 1-14, 2020.

[40] R. N. Tuncay, O. Ustun, M. Yilmaz, C. Gokce, and U. Karakaya, "Design and implementation of an electric drive system for in-wheel motor electric vehicle applications," 2011 IEEE Veh. Power Propuls. Conf. VPPC 2011, no. March 2014, 2011. 